\title{
Influences that undermine learners' perceptions of autonomy, competence and relatedness in an online context
}

\author{
Maggie Hartnett \\ Massey University, New Zealand
}

\begin{abstract}
Online learning has grown considerably in recent years. However attrition rates from online courses indicate that not all learners are successful in such settings, and various factors have been identified as crucial to learner persistence. Research evidence suggests that motivation is one such factor. This study builds on previous studies by using self-determination theory (SDT) as an analytical framework to explore, in-depth, the motivation of pre-service teachers situated within an online learning context. In particular, the underlying concepts of autonomy, competence and relatedness from SDT were adopted as critical lenses to identify social and contextual influences which undermined the psychological needs of these learners. Most prominent among these in the current study were: high workload, assessment pressure, perceptions that the learning activity lacked relevance (autonomy-undermining), unclear and complicated guidelines, insufficient guidance and feedback from the instructor (competence-undermining), and communication issues with peers (relatednessundermining). By not exclusively focusing on learners' autonomy needs as others have done, the paper offers a more extensive picture of undermining influences on motivation than has been previously identified in online studies.
\end{abstract}

\section{Introduction}

In recent years, online education has undergone a period of considerable change. The growth of the Internet and related technologies has resulted in a merging of online teaching and learning into the routine practices of higher education institutions (Haythornthwaite \& Andrews, 2011). Online learning has a number of potential benefits, not least of which is the ability to overcome the temporal and spatial restrictions of traditional educational settings. In doing so, it provides learners with flexibility and autonomy in determining when, where and how they learn (Bates, 2005). Despite this, research also shows that not all learners are able to successfully manage their learning in online environments (Rienties et al., 2012). For example, ongoing concern over attrition rates in online courses (Lee, Choi, \& Kim, 2013), has prompted a call for further research to add to our understanding of the complexity of factors at play in these environments (Luppicini, 2007). Motivation is one such factor (Kim \& Frick, 2011). The aim of this paper is the in-depth exploration of the multiple influences that combine in complex ways to undermine learner motivation in an online context.

\section{Motivation}

“To be motivated means to be moved [original emphasis] to do something.” (Ryan \& Deci, 2000, p. 54). Motivation has been described as the engine of learning (Paris \& Turner, 1994) and can influence what, when, how and if we choose to learn, and is a significant factor in performance (Schunk, Meece, \& Pintrich, 2014). Motivation involves goals that provide the impetus for purposeful, directed action. It has been shown to play an important role in determining whether a learner persists in a course, the level of engagement shown, the quality of work produced, and the level of achievement attained (Schunk, et al., 2014). Although motivation is frequently treated as a single construct, research shows that it is complex, variable and influenced by many interrelated social and contextual factors (Hartnett, St. George, \& Dron, 2011). Understanding the ways in which social and contextual features may influence the motivation of learners, therefore, has important practical implications for those involved in both teaching and learning in online contexts (Kim \& Frick, 2011).

\section{Self-determination theory}

Self-determination theory (SDT) is a macro theory of motivation that is built on the fundamental principle of learner autonomy (Ryan \& Deci, 2000). SDT has been used extensively to underpin research exploring motivation of learners in educational settings (Deci \& Ryan, 2008) that include face-to-face (Brophy, 
2010) and online contexts (Rienties, et al., 2012). This theory argues that all humans have an intrinsic need to be self-determining or autonomous, as well as to feel competent, and to experience a sense of connectedness to others.

Autonomy "refers to being the perceived origin or source of one's own behaviour" (Ryan \& Deci, 2002, p. 8). When autonomous, students attribute their actions to an internal perceived locus of causality and experience a sense of choice over their actions (Reeve, Ryan, Deci, \& Jang, 2008). Competence "refers to feeling effective in one's ongoing interactions with the social environment and experiencing opportunities to exercise and express one’s capacities” (Ryan \& Deci, 2002, p. 7). Support for competence is necessary to facilitate motivation (Ryan \& Deci, 2000) and external events convey information about a person's competence or skill level. Relatedness "refers to feeling connected to others" (Ryan \& Deci, 2002, p. 7) and autonomous motivation is more likely to flourish in situations where learners experience a secure sense of belonging (Deci \& Ryan, 2008).

In addition to the psychological needs outlined, SDT details a continuum of types of motivation "in terms of the extent to which the motivation for one's behaviour emanates from one's self” (Ryan \& Deci, 2000, p. 61). Importantly, it identifies several types of extrinsic motivation which vary in terms of autonomy or self-determination, from the classic externally controlled motivation through increasingly more autonomous, volitional and valued types of extrinsic motivation. The degree to which an individual expresses self-determined forms of extrinsic motivation, or alternatively, intrinsic motivation (this being the most self-determined type of motivation), depends on whether their innate needs of autonomy, competence and relatedness are met by factors within the learning environment (Ryan \& Deci, 2000). In other words, these three psychological needs are intertwined and together facilitate or undermine motivation of learners.

Research in face-to-face contexts shows that autonomy support within the learning context leads to more self-determined motivation among learners (Deci \& Ryan, 2008). Conversely, external demands such as deadlines, directives, compliance requests as well as use of rewards to control behaviour serve to undermine motivation (Deci \& Ryan, 2008). Choice has also been shown to be supportive of learners' autonomy needs (Reeve, et al., 2008). However, it is the perception of choice, or lack of it, rather than the actual choices that is critical in terms of self-determination (Katz \& Assor, 2007).

Support for the competence needs of learners is also necessary to facilitate motivation (Schunk \& Zimmerman, 2006). The provision of structure has been shown to be important in supporting competence needs and facilitating self-determined types of motivation (Jang, Reeve, \& Deci, 2010). Structure may include such things as explicit, detailed information that clarifies expectations; provision of informational feedback; and responsiveness to student questions, comments and suggestions (Reeve, 2009). In addition, learning activities designed to be optimally challenging, where the challenge of the task is high and reasonably well-matched to learners' skill levels (Csikszentmihalyi, 1985), encourage feelings of capability and motivation. Conversely, if learners do not perceive the structure to be supportive, such as course requirements that appear overwhelming or activities that are too easy or too difficult can result in motivation being undermined (Reeve, 2009; Van Etten, Pressley, McInerney, \& Liem, 2008).

Support for relatedness needs further impacts on motivation to learn. The more an individual experiences having their autonomy and competence needs met within supportive interpersonal relationships, the more connected and trusting they feel towards those people (Ryan, La Guardia, Solky-Butzel, Chirkov, \& Kim, 2005). In line with this, teacher involvement in terms of the amount of time invested, care taken, attention given and recognition (Brophy, 2010), as well as opportunities for collaborative work (Blumenfeld, Kempler, \& Krajcik, 2006) have been shown to be powerful motivators. Conversely, difficulties in relationships with teachers and other learners have been associated with a corresponding undermining of motivation (Martens \& Kirschner, 2004).

\section{SDT and motivation to learn in online settings}

Research highlights the importance of the relationships between learners' perceptions of selfdetermination and their online behaviour (Chen, Jang, \& Branch, 2010; Hartnett, et al., 2011; Sørebø, Halvari, Gulli, \& Kristiansen, 2009). Exploration of motivation in virtual learning environments using 
SDT as a theoretical framework has shown that feedback, the instructor's role in online discussions, choice, competence, challenge, interest, relevance and collaboration all influenced student intrinsic motivation to learn in the various online learning contexts (Artino, 2007; Hartnett, St. George, \& Dron, 2014; Rienties, et al., 2012; Shroff, Vogel, \& Coombes, 2008; Xie, DeBacker, \& Ferguson, 2006). Previous studies have also shown that lack of teacher input, not having a genuine reason to communicate online with peers, low self-efficacy, as well as time and technology constraints can lower motivation (Artino, 2007; Cheung, Hew, \& Ling Ng, 2008; Hartnett, et al., 2011; Moos \& Azevedo, 2008; Xie, et al., 2006).

However, with the exception of research by Hartnett, et al. (2011), none of the above studies clarified the underlying reasons why the identified contextual factors supported or undermined learner motivation. It can be argued, for example, that unclear guidelines and poorly articulated expectations can impede the learning process thereby undermining a learner's need to feel effective and competent. In other words, it is the lack of support for learners' competence needs that undermines intrinsic motivation in this case, rather than learners' autonomy needs as some have suggested (Xie, et al., 2006).

\section{Method}

\section{The study}

This paper utilises the dataset of a larger study (Hartnett, 2010) that explored the motivation of preservice teachers situated within real-life online learning contexts. While the main study explored and identified a broad range of influences that supported as well as undermined learners' motivation in two online learning contexts, results presented and discussed here focus on only those that undermined perceptions of motivation among learners in one context. This is so that the complex interplay of factors that emerged as undermining motivation to learn can be discussed in depth. Factors that can support motivation in online contexts are explored elsewhere (Hartnett, et al., 2014). The research question that guides the findings reported here is:

In what ways do social and contextual factors undermine pre-service teachers' autonomy, competence and relatedness needs in an online learning environment?

\section{Case study}

This study was exploratory in nature and sought to identify, explore and understand pre-service teachers' online learning experiences as they related to their motivation to learn in a specific online context. Therefore, the methodology adopted was case study because such an approach can be of value where the research aims to investigate a complex phenomenon embedded in the real world, where the scope is difficult to define and can only be understood within context (Yin, 2009). Purposive sampling (Patton, 2002) was adopted where predetermined criteria of importance were used to ensure relevance to the research question. In particular, (1) the course was required to be predominantly online with only limited resources provided by alternative methods such as print-based materials, and (2) course expectations required students to participate within the online learning community as an integral part of coursework.

\section{Procedures}

Ethical approval to undertake the study was gained prior to commencement. Data collection procedures comprised online questionnaires and semi- structured interviews (undertaken after the completion and marking of relevant coursework); and online asynchronous discussion transcripts (generated during the course but collected after all coursework was completed, graded and results submitted). The questionnaire collected demographic information; self-report measures of motivation using the SDT situational motivational scale (Guay, Vallerand, \& Blanchard, 2000); and open-ended questions developed to gain insight into possible relationships between social and contextual influences and learners' motivation. Interviews were undertaken to further explore participants' experiences, how the context influenced their thinking, feeling, behaviour, and motivation in an online environment. Open-ended questionnaire and interview questions were developed with reference to the SDT literature (Ryan \& Deci, 2002) and more general literature on motivation in learning (Brophy, 2010). For complete questionnaire and interview 
instruments see Hartnett (2010). Collecting online asynchronous discussion transcripts enabled perceptions of both lecturers and student participants, evident from interview and questionnaire data, to be confirmed or anomalies highlighted. Findings presented here draw on these data.

\section{Context and participants}

The course that provided the context for the case study presented here was situated within the larger context of a pre-service teacher education programme within a New Zealand tertiary institution. Students in this programme were preparing to teach in New Zealand primary (i.e. elementary) schools. The course was considered Internet-based rather than fully online because students received some print material (study guide) and digital resources (CD-ROM) at the beginning of their course. The course was hosted within the institution's online learning management system.

The case itself was situated within a compulsory integrated science and technology course. Teaching staff consisted of a course coordinator with science expertise and a tutor with technology expertise. The tutor was responsible for the majority of the online teaching. Students typically took this course in the third and final year of their degree (which they were completing by distance) and had substantial prior experience of online learning and group assignments. The case study itself focused on a Problem-Based Learning (PBL) assignment worth $60 \%$ of the final mark. This was undertaken over a 6 week period in which students were required to work collaboratively in small groups. PBL is an instructional approach built around authentic, ill-structured problems that are complex in nature (Loyens, Kirschner, \& Paas, 2011).

An invitation to participate in the study was extended to all students enrolled in the course via a message posted within the online learning environment. Collectively, 12 student participants and two lecturers took part in the study. Student participants were located throughout New Zealand and undertook their courses at a distance from the main campus. The student participant group, matching the general demographics of the course, comprised 1 male and 11 females, with participants' ages ranging from 24 to 50 and $92 \%$ in the over 30 age group. The wider study (Hartnett, 2010) showed that participants' achievement in the course was typical of the cohort as a whole.

\section{Data analysis}

Both inductive and deductive analysis occurred within this research investigation. SDT (i.e. the psychological needs) provided sensitising concepts with which to explore the qualitative data (Blumer, 2006). An inductive approach geared to allowing additional patterns, themes and categories to emerge from the data, occurred concurrently (Patton, 2002). This approach also allowed for the possibility of disconfirming influences to emerge including themes that indicated motivation was supported rather than undermined and themes that did not fit within the SDT framework. The qualitative analysis software package NVivo was used to facilitate and manage the complex, iterative process of analysing the qualitative data.

This process involved reading and re-reading all qualitative data to get a sense of the breadth of responses and the possible range of codes needed to identify themes. Each theme was assigned a code and each coded piece of text was placed at a node named in such a way that it described the essence of the idea identified. In this way, chunks of text with similar ideas were able to be stored together. These pieces of text varied in length and were coded at all relevant nodes depending on whether single or multiple themes were identified.

\section{Results}

A range of social and contextual influences emerged that learners' perceived as undermining their autonomy, competence and relatedness needs (see Table 1). It is important to note that no one factor undermined all the psychological needs of learners and that learners' perceptions of the extent to which this occurred were formed from multiple influences that combined in complex ways. For example, approximately half of the participants felt they had received insufficient guidance and found the PBL activity lacked relevance, while the remainder felt the guidance received was sufficient and found the activity highly relevant (Hartnett, et al., 2014). 
Australasian Journal of Educational Technology, 2015, 31(1).

Table 1

Undermining influences of autonomy, competence and relatedness

\begin{tabular}{|c|c|}
\hline Undermining Influences & Frequency count \\
\hline \multicolumn{2}{|l|}{ Autonomy } \\
\hline 1. High workload & 81 \\
\hline 2. Salience of assessment & 63 \\
\hline 3. Lack of relevance & 61 \\
\hline 4. Course expectations \& language perceived as controlling & 58 \\
\hline 5. Time constraints & 37 \\
\hline 6. Technology constraints & 34 \\
\hline 7. Limited choice & 24 \\
\hline 8. Workload inequity & 23 \\
\hline 9. Limited input in group decisions \& tasks & 20 \\
\hline \multicolumn{2}{|l|}{ Competence } \\
\hline 1. Unclear/complicated guidelines & 63 \\
\hline 2. Insufficient guidance \& feedback & 57 \\
\hline 3. Judgements of low self-efficacy & 54 \\
\hline 4. Teacher input gradually reduced & 36 \\
\hline 5. Resource perceived as not useful & 28 \\
\hline 6. Challenge too great & 17 \\
\hline \multicolumn{2}{|l|}{ Relatedness } \\
\hline 1. Communication issues \& disagreements & 58 \\
\hline 2. Limited opportunities for interactions in wider class & 33 \\
\hline
\end{tabular}

\section{Autonomy-undermining themes}

Nine main themes emerged as undermining learners’ perceptions of autonomy (see Table 1).

Perceptions of high workload emerged as the most salient theme that undermined the autonomy of participants. Comments that it "took a lot of time and effort to complete, and became all-consuming" (Student5 - questionnaire) and "it was a heavy workload compared to other assignments. I'll be honest it was one of the heavier loads" (Student10 - interview) were echoed throughout the participant group.

The salience of assessment was also prominent during the PBL task because the assignment was worth $60 \%$ of the final course mark. "I did not enjoy the fact that [the PBL] assignment ... counted for $60 \%$ of the total course mark" (Student5 - questionnaire ) and "the fact that $60 \%$ of the mark came from ... one assignment and if you missed the mark on that then you are you're lost, you failed ... and to me that's really tough. ... and that worried me" (Student6 - interview) were indicative of comments made by participants. Even students who reported feeling more autonomous throughout the activity were aware of the high stakes nature of the PBL assessment: "I mean this one was 60\%. It is a huge amount of marks that you can either lose or get” (Student10 - interview).

A perception of lack of relevance was the next most important influence that undermined autonomy. Learners who questioned the relevance of the PBL activity did so at several levels. These included: how 
PBL related to any knowledge or skills directly transferable to the classroom: "nothing that I can practically use in a primary school classroom" (Student5 - questionnaire); how it connected to their prior experience and knowledge of science and technology: "I doubt I will use this model in school anytime soon. It does not look like any integrated subjects I've seen in schools” (Student1 - questionnaire); and whether it had any personal relevance: "[PBL is] aimed at intermediate [year 7 and 8] kids or year 5 and 6 and most of us ... aren't aiming to teach at that level. So it is a waste of time in some aspects” (Student6 interview).

Course expectations required students to interact with each other online within their collaborative groups, assisted by the lecturers. In particular, the expectation that required students to be actively discussing their ideas with other group members engendered a sense of compulsion that undermined autonomy needs: "when you're doing an online course and you're doing it with people that you talk to every day, there doesn't seem to be an understanding of the fact that we were working, we had to be seen to be working ... we were expected to be putting something on [the asynchronous discussion forum], on a regular basis" (Student6 - interview). In some cases, this resulted in "the only time we used it is when we thought our lecturer was gonna come on and check to see whether we'd actually gone through the process correctly" (Student11 - interview). This sense of compliance occurred because students chose to interact via alternative, synchronous technologies to bypass perceived technology constraints (see below).

Furthermore, several participants perceived the communications from lecturers as controlling. For example, the following message: "A review of the PBL groups reveals that no/or little interactions relating to the set tasks (phases) have occurred on line. While you may indeed be meeting face-to-face please note it is our expectation that the phases that ask you to provide comment on must be posted on line. We note many groups up to date or exceeding the requirements” (Tutor - asynchronous discussion), resulted in feelings of pressure for some participants: "after that little reminder from [the tutor] I felt a little pressured to have a go” (Student1 - asynchronous discussion).

The combination of high workload and salience of assessment contributed to the emergence of a further theme of perceptions of time constraints. The common observation "that the timeframe was very short and we were scrambling to get the project completed to our satisfaction" (Student11 - questionnaire) and "time constraints ... starts to limit your choice" (Student7 - interview) left many participants feeling that much of the learning process was beyond their control.

Moreover, a common perception among the participants emerged that the chosen technology (i.e. asynchronous discussion board) constrained the PBL activity. Communicating asynchronously was seen as "very time consuming” (Student7 - questionnaire) and "slowed down the communication” (Student6 interview). It also slowed down decision making: "when it came time to having to make a group decision on things. Sometimes this ended up taking several days just to decide" (Student9 - questionnaire). The net result of these multiple external pressures saw learners turning to synchronous forms of communication (e.g. Skype, phone, face to face) that better suited the frequent, ongoing collaborative decision-making processes of the PBL task.

The next theme to emerge related to perceptions of limited choice. Those who expressed a lack of choice focused on the compulsory nature of the programme/course/assignment: "we didn't have any choice about doing the course" (Student6 - interview); or the requirement to work in small groups: "it was just a case of find a group and get into a group and get on with it” (Student12 - interview).

A further theme related to perceptions of having limited input into the tasks and decisions-making processes within their small group or not being consulted at all. In other words, several participants perceived their contributions as having little or no influence in the overall actions of the group. For example, "I kind of put my argument forward but it got knocked out straight away without any further discussion and I thought it was actually a quite valid science and technology investigation" (Student11 interview) and "when it came to putting the assignment together X did the presentation ... and we didn't get to see the assignment before it was submitted. So there wasn't any editing. There wasn't any opportunity ... and that's a really tough one” (Student1 - interview). 
The final theme to emerge that undermined learners' autonomy needs was the perception of workload inequality among some PBL group members. Several participants described how some group members contributed more than others and the difficulties this presented: "I learnt that group members may be unreliable, non-collaborative or have little integrity ... equity issues are huge when it comes to collaborative assignments" (Student1 - questionnaire) and "some students in our group did more work than others and some have different or higher/lower expectations than others" (Student11 - interview). Group members who were perceived as not doing their share were a source of frustration as the following comment indicates: "I did get a bit resentful when people didn't do what they were supposed to do" (Student1 - interview).

\section{Competence-undermining themes}

Six important themes emerged from the data that contributed to the undermining of learners' needs to feel capable and effective. Of these, perceptions of unclear and complicated guidelines emerged as the most important theme. The complexity and quantity of the information provided within the online environment was a primary reason for this: "I was feeling as though I was floundering to start off with and I like things very clear and very structured so I know what I was doing and found that was too confusing” (Student12 - interview) and "I didn't understand the learning out[comes], the goals that were set 'cause there were too many. ... [It was] too big, too wide” (Student11 - interview).

In addition to a complex assignment structure, perceptions of insufficient guidance and feedback from the lecturers in the online environment emerged as a highly salient theme that undermined several participants' need to feel capable. This state of uncertainty engendered is highlighted in the following comments: "sometimes we just lacked direction because we didn't get it from the lecturer" (Student11 questionnaire) and "I think there probably should have been a lot more scaffolding at the beginning" (Student12 - interview). This sense of uncertainty was summed up by the unanswered question raised by several participants in the interviews “are we on the right track?” (Student6 - interview).

Judgements of low self-efficacy resulted from some participants questioning their ability to demonstrate science and technology understanding within the context of a PBL online activity. A perception of a tenuous link between previous learning experiences and the PBL assignment was one reason for this: "we did technology in year one ... and I can’t say I could link what I did then with what I did now. ... It was just it was like two different ... courses almost” (Student5 - interview). In some cases this led to procrastination and feelings of anxiety: "I was slow getting underway I think because when I looked at it and thought oh my goodness what do I do here? I was feeling as though I was floundering to start off with" (Student12 - interview).

The gradual reduction of lecturer input, inherent in the design of the PBL online activity, in some cases, undermined the competence needs of participants. This was particularly true for students who were already questioning their ability to complete the task successfully (i.e. judgements of low self-efficacy): "when you get a gap [in knowledge] or when you don't understand then where do we go to for support? I know they're saying they're trying to drop off their support but that does not mean they can't give us the guidelines to work through" (Student11 - interview).

A further theme to emerge was a perceived lack of useful resources. This was primarily because the resources failed to provide sufficient information or information in a way that enabled learners to develop their understanding of curriculum integration and PBL. Lack of additional recommended resources caused a problem as this was something students were used to from past study experiences: "[if] you want to go read more, there's [sic] all these recommended sources that are there for a reason. This course didn't have any of that" (Student5 - interview).

Finally, participants who experienced the PBL assignment as challenging beyond their perceived capabilities expressed feelings of apathy or a lack of control consistent with less self-determined motivation: "I just felt the challenge was too great for me and I tended towards the end to just not bother whatever will be will be and we'll just have to live with it” (Student12 - interview). However, not all participants experienced the assignment as challenging beyond their capabilities in the wider study 
(Hartnett, 2010). Those who experienced it as an achievable challenge talked about a sense of enjoyment and satisfaction in their achievements.

\section{Relatedness-undermining themes}

A further two themes emerged from the data that contributed to the undermining of learners' relatedness needs. Generally, participants whose relationship needs were not met during the PBL assignment described communication issues and disagreements with their peers. The following examples are indicative of those made by participants who expressed dissatisfaction with their relationships: "we did check in each night but because each of us wasn't communicating within our group so much, we were just looking to see if there was any announcements or anything we needed to know ... we ended up just drifting along” (Student12 - interview) and "because A hadn't been in the conversation she missed the fact that when we were doing our science experiment we were testing things ... and when you're not in the conversation when you're not present ... and you're just skimming over the top, then it messes things up” (Student1 - interview).

Limited interaction with the wider class exacerbated this situation as the nature of the assignment necessitated that learners work within their small groups, almost exclusively, during this period of time. The following comment reflects those of the participant group as a whole: “as a class, we didn't have a lot of interaction. ... It was a very isolated course in that sense that you were basically working with individuals you chose as your group” (Student10 - interview).

\section{Discussion}

While influences that undermined learners' motivation are the focus here, it is important to note that despite the features of the learning activity being the same, some influences identified were viewed as supportive by some of the learners in this case study (Hartnett, 2010). What this indicates is that motivation in this context resulted from the complex interplay between individuals and the environment in which they were situated.

\section{Influences that undermined perceptions of autonomy}

All participants commented on the heavy workload required to successfully complete the activity. The pressure of workload was further exacerbated by the high stakes nature of the task (60\% of the overall course mark). The combination of high workload and salience of assessment also resulted in perceptions of time constraints among the entire participant group. Furthermore, the collective pressures of workload, assessment and time highlighted the constraining nature of the technology. In other words, the asynchronous communication medium was perceived by all participants as being not well-suited to the frequent, ongoing, collaborative, decision-making processes characteristic of PBL. This meant that course expectations, which required students to communicate with each other via the asynchronous discussions, assisted by the lecturers, were perceived as controlling as well as inefficient by several participants. This controlling aspect was further emphasised when online communications from lecturers contained directives or suggestions that were perceived as directives. Collectively, these influences were experienced as external pressures and left several participants feeling that much of the learning process was beyond their control.

These findings are consistent with prior research that highlights that external events such as deadlines, evaluation and use of controlling language (Reeve, 2009), time pressures (Deci \& Ryan, 2008; Xie, et al., 2006), lack of alignment between the technology used and the PBL process (Loyens, et al., 2011), as well as the technological medium itself (Anderson, 2006) can have a detrimental effect on perceived autonomy. Other research has also identified that all technology imposes its own constraints (Dron, 2007), the need to match appropriate technology with the learning task (Xie, et al., 2006), the demanding nature of authentic tasks (Woo, Herrington, Agostinho, \& Reeves, 2007) and that requirements to interact online imposed by lecturers can have a detrimental effect on personal agency (Anderson, 2006). Therefore, it is important to consider the possible implications of these context specific factors as they may undermine student motivation. 
In addition to the above, the dominance of the PBL task in what was an integrated science and technology course caused several participants to question its relevance to the overall course objectives. This, in turn, caused them to question the value of what they had learned. Furthermore, the lack of explicit connection to 1) classroom practice, and 2) previous science and technology experience and knowledge meant the activity held little value for some participants. Lack of alignment of the task with learners' personal goals, values and interests, both while doing the task and beyond, also undermined learners' perceptions of autonomy.

Learners who do not value an activity often feel this way because it does not hold any inherent interest for them or they cannot see why it is important (Van Etten, et al., 2008). Given the strong evidence linking relevance and personal importance with motivation among learners in traditional (Reeve, et al., 2008; Ryan \& Deci, 2000) and online settings (Hartnett, et al., 2011), learners' perceptions of value are an important consideration. This is made even more challenging for the teacher in an online setting where an individual student's appreciation for a particular task may be difficult to determine. It also highlights the importance of online teachers (like other teachers) providing explicit information to learners about the value and relevance of what is being learned even when individuals' goals and interests are not known.

Lack of choice or feeling constrained for choice was a further factor perceived as undermining autonomy by approximately half of the participants. Obviously, a number of actual choices were available to learners but as this finding demonstrates and other studies suggest (Katz \& Assor, 2007; Patall, Cooper, \& Robinson., 2008), provision of choice does not necessarily translate to perceptions of choice by learners. If learners do not perceive that meaningful and relevant choices are available to them, simply offering choices will not encourage more autonomous motivation (Artino, 2007).

Participants who perceived they had limited or no input into the decision-making processes of their group (i.e. that their contributions had little or no influence) perceived that their autonomy needs were unsupported. This was further heightened, for some, by perceptions of inequitable workloads among group members. Not being able to significantly change the situation contributed to perceptions of having little or no control over their learning, a finding noted elsewhere (Blumenfeld, et al., 2006).

Collaborative group work has been shown to facilitate learning in a number of important ways including motivational aspects (Slavin, 2011). However, research has also shown that high quality cognitive engagement is hard to achieve (Blumenfeld, et al., 2006) and students often dislike collaborative group work because of its dependence on all participants making adequate contributions to the group effort (Slavin, 2011). The unfairness and decrease in motivation students feel when required to work with group members who do not contribute sufficiently, has also been highlighted previously (Van Etten, et al., 2008).

\section{Influences that undermined perceptions of competence}

Half of the study participants perceived that the assignment guidelines were unclear or overly complicated. This was despite extensive information being provided up-front to support learners and encourage them to direct their own learning. An unintended consequence, however, was that some felt overwhelmed by the amount and detail of information. In conjunction with this, learners perceived that the ongoing guidance and feedback they received from the lecturers were insufficient for their needs. This perceived lack of guidance was made more salient by the PBL approach adopted.

The PBL activity commenced with significant input from the lecturers and was gradually reduced as learners clarified their approach and direction and took ownership of their problem. But for students who were already struggling with perceptions of low self-efficacy, the reduction of guidance and feedback inherent in the design of this online PBL activity proved to be in direct opposition to their need to feel capable. Lack of previous related experience with PBL and unclear connections with prior science and technology knowledge were the primary reasons for lowering the self-efficacy of participants. The perceived lack of usefulness and relevance of the resources compounded this view. This was primarily because participants felt the available resources failed to provide sufficient information to support the development of their understanding of curriculum integration and PBL more specifically. This led several participants to feel that the activity was challenging beyond their perceived capabilities and resulted in 
feelings of anxiety, and in some cases helplessness. Collectively, these influences led these learners to perceive that their competence needs were unsupported as they felt unable to make accurate judgements about their ability to succeed.

Previous research (Jang, et al., 2010; Rienties, et al., 2012) indicates that in order to meet a learner's need for competence, positive structure in terms of the right amount, quality and clarity of information is necessary. If learners do not perceive the structure to be supportive, this can lead to confusion and anxiety (Reeve, 2009), as was the case for several participants. Course outlines that make course requirements appear overwhelming have also been shown to undermine motivation (Van Etten, et al., 2008). Brophy (2010) makes the observation that struggling students often need more ongoing, explicit structuring and scaffolding during the learning process. In line with this, students commented that the scaffolding they received was insufficient, particularly as lecturer input was gradually reduced as the activity progressed.

This is not surprising given frequent, informative performance feedback is necessary for an individual to make cognitive evaluations about his or her perceived competence level (Schunk \& Zimmerman, 2006). In line with this, Loyens et al. (2011) have argued that learner-centred approaches such as PBL are most effective when students have the necessary prerequisite knowledge and some prior experience. The importance of designing tasks that are optimally challenging and the need to provide sufficient and appropriate resources to scaffold learners through the learning tasks have been identified previously (Brophy, 2010). Other research (Jang, et al., 2010; Reeve, 2009) has also shown that self-determined motivation is most prevalent in learning environments where teachers provide high structure (e.g., provision of regular, constructive feedback) in an autonomy supportive manner (e.g., using informational rather than controlling language). Conversely, too little instructor input has also been shown to be problematic in terms of motivation (Xie, et al., 2006).

It is interesting to note that these findings differ from the notion that the greater the autonomy of the learner the less dialogue and structure is needed which is central to Moore's (2007) theory of transactional distance and the self-directed nature of PBL (Loyens, et al., 2011). This points to a tension between one interpretation of self-direction as requiring minimal structure and another that highlights the need for structure because it supports self-direction by fulfilling an underlying need for competence (Jang, et al., 2010).

\section{Influences that undermined perceptions of relatedness}

Communications between group members characterised by problems and disagreements contributed to feelings of isolation and disconnection experienced by some participants. These issues included lack of communication within the group, misunderstandings about what was being discussed and disagreements about possible courses of action to take.

Furthermore, the PBL activity was perceived primarily as a collaborative group exercise that offered little opportunity to interact with other learners in the wider class context. This was not the intention of the lecturers who saw the importance of developing a learning community within the wider class. However, perceptions of participants suggest that the development of a class-wide online community was unsuccessful. This meant that learners were reliant on the peers within their small group to meet their relatedness needs. If, as was the case for several participants, they found themselves in difficult relationships with their collaborative partners their need to belong and feel connected was undermined.

Feelings of belonging and connection via interaction in online environments have been shown to have a positive motivational effect on learners (Xie, et al., 2006). In line with this, previous research has highlighted the importance of providing opportunities for learners to build personal relationships with each other to promote the development of an online community (Rovai, 2007). Brophy (2010) argues that collaborative learning will only work in some contexts, specifically those in which a community of learners has already been established. If this is not the case then conflict and hurt feelings may feature more prominently than collaboration.

When requiring learners to work within collaborative groups, instructors need to provide a rationale with solid support for the benefits of such an approach. Once established, groups require ongoing input from 
the teacher, as too little input has been shown to be problematic when there is a need for intervention (Jones \& Issroff, 2007).

\section{Implications}

This study has demonstrated that perceptions of autonomy, competence and relatedness by learners (which contribute towards how self-determined and therefore how motivated they feel) were influenced by online teaching approaches, learning activity design and the social features of the tasks in which they were engaged. This aligns with our current understanding of the situated nature of learning (Wegerif, 1998). The message here, though, is that when the differing circumstances of students within the learning context are not accommodated this can undermine the expression of more self-determined motivation among some learners. The identification of a wide range of social and contextual influences and clarification of how these affected learners' perceptions of their psychological needs being unsupported, has resulted in a richer model of influences on motivation than has been previously attempted in online studies (e.g., Xie, et al., 2006).

Teachers and instructional designers, therefore, need to be cognisant of the important role they play in influencing learner motivation in terms of learning design and teaching. In particular, issues of high workload coupled with time constraints, an over-reliance on summative assessment and lack of explicit links between activities (e.g., online discussions) and their relevance to learning objectives can result in learners feeling less autonomous in online learning contexts. If the digital technologies being used and the activity learners are being asked to undertake are not aligned this, too, can have a detrimental effect on perceived autonomy. Furthermore, it's not enough to simply offer choice to learners. If those choices are not seen as meaningful the perceived value of the activity can be undermined.

Guidelines and expectations at the outset of an activity that are unclear, overly detailed or ambiguous can undermine the competence needs of certain learners. Moreover, learning activities that are too difficult, fail to take into account the prior knowledge, skills and experience of learners can also undermine a learner's need to feel capable as not all students will believe they have the necessary knowledge and skills to succeed.

How ongoing guidance is provided is important and online instructors need to be prepared to offer support in a differentiated manner. That is, learners who feel overly challenged or are having difficulties may need more overt structure (even when the design of an activity calls for an increasingly learnerdirected approach). If this is not available to learners when and how they need it then the activity may be seen as challenging beyond their perceived capabilities (i.e. the task being out of the learner's control) and result in anxiety and procrastination. The tone used when communicating course expectations as well as feedback and ongoing guidance is also important. This is because lack of participation may be a sign of low self-efficacy. If communications are perceived as controlling in any way (i.e. seeking compliance) then motivation is likely to be undermined.

Peers also play an important role in influencing the motivation of other online learners and instructors need to be cognisant of the ways in which unsupportive relationships among peers have the potential to undermine motivation if problems emerge that are not addressed. This is particularly important when learners are engaged in collaborative assignments where success is dependent on input from all group members and engagement with the whole class is limited.

What these findings demonstrate is that support for the motivation needs of learners needs to be systematically incorporated into online courses. Most importantly, the relevance and value of activities need to be clearly identified and linked to learning objectives to help learners understand how the activity can aid in the realisation of personal goals, aspirations and interests, both in the short and longer term. Differentiated support is required to meet the differing needs of learners with more overt structure and feedback required in some cases. Additionally, by building strong relationships with and between learners online instructors are in a better position to accurately respond to situational factors that could potentially undermine learner motivation. 
While this study adds to our understanding of the complex influences that can undermine learners' motivation in online contexts, further research that investigates if and how motivation changes throughout the duration of an activity, course and programme is needed. Doing so will shed light on the role motivation plays in learner persistence across a variety of online learning contexts including MOOCs.

\section{Limitations}

As with all research, there are a number of limitations with this study. The use of case study methodology meant that findings are associated with a particular chosen context, namely one course that formed part of a pre-service teacher education programme within a single New Zealand university. It is important to note that the purpose of this study was to explore ways in which motivation to learn was undermined within a specific context, not to provide, nor to empirically validate, a model. The findings are generalisable only in the sense that it is possible to say from these observations alone that motivation is a complex, multifaceted and situation-dependent construct in which learners, their teachers, the learning design, the technological and the organisational context have important and intertwined roles.

\section{Conclusion}

With the adoption of self-determination theory, in particular the underlying concepts of autonomy, competence and relatedness, this study has uncovered a range of social and contextual factors that undermined motivation in the context described here. In doing so, this study has developed, evaluated and provided evidence for a more extensive framework of undermining influences on motivation than has been previously attempted in online studies. Importantly, the identification of a range factors that constrain motivation, most notably high workload, a focus on assessment, perceptions of lack of relevance, and unclear and complicated assignment guidelines, highlights the dynamic interplay of factors that can undermine learner motivation.

These findings are not intended to be used as a definitive list or a set of prescriptions. Nor will all factors affect all people in all contexts. Rather, they need to be considered as indicators situated within specific online learning and teaching contexts. They do, however, provide a starting point for online practitioners, course designers and those responsible for online quality assurance to re-consider their practice in terms of how certain actions can create conditions that undermine the psychological needs, and therefore the motivation, of learners. The interplay of factors will vary within any given context and will almost certainly be different for every participant within it. But unless this complexity is recognised and understood, we run the risk of undermining the motivation of learners.

\section{References}

Anderson, B. (2006). Writing power into online discussion. Computers and Composition, 23(1), 108-124. doi:10.1016/j.compcom.2005.12.007

Artino, A. R. (2007). Online military training: Using a social cognitive view of motivation and selfregulation to understand students' satisfaction, perceived learning, and choice. Quarterly Review of Distance Education, 8(3), 191-202

Bates, A. W. (2005). Technology, e-learning and distance education (2nd ed.). New York: RoutledgeFalmer. doi:10.4324/9780203463772

Blumenfeld, P. C., Kempler, T. M., \& Krajcik, J. S. (2006). Motivation and cognitive engagement in learning environments. In R. K. Sawyer (Ed.), The Cambridge handbook of the learning sciences (pp. 475-488). Cambridge, NY: Cambridge University Press.

Blumer, H. (2006). What is wrong with social theory? In N. K. Denzin (Ed.), Sociological methods: A sourcebook (pp. 84-96). New Brunswick, NJ: Aldine Transaction.

Brophy, J. (2010). Motivating students to learn (3rd ed.). New York, NY: Routledge.

Chen, K.-C., Jang, S.-J., \& Branch, R. M. (2010). Autonomy, affiliation, and ability: Relative salience of factors that influence online learner motivation and learning outcomes. Knowledge Management \& ELearning: An International Journal 2(1), 30-50

Cheung, W. S., Hew, K. F., \& Ling Ng, C. S. (2008). Toward an understanding of why students contribute in asynchronous online discussions. Journal of Educational Computing Research, 38(1), 29-50. doi:10.2190/EC.38.1.b 
Csikszentmihalyi, M. (1985). Emergent motivation and the evolution of the self. In D. A. Kleiber \& M. L. Maehr (Eds.), Advances in motivation and achievement (Vol. 4, pp. 93-119). Greenwich, CT: JAI Press.

Deci, E. L., \& Ryan, R. M. (2008). Self-determination theory: A macrotheory of human motivation, development and health. Canadian Psychology, 49(3), 182-185. doi:10.1037/a0012801

Dron, J. (2007). Control and constraint in e-learning: Choosing when to choose. Hershey, PA: Information Science. doi:10.4018/978-1-59904-390-6

Guay, F., Vallerand, R. J., \& Blanchard, C. (2000). On the assessment of situational intrinsic and extrinsic motivation: The situational motivation scale (SIMS). Motivation and Emotion, 24(3), 175-213. doi:10.1023/A:1005614228250

Hartnett, M. (2010). Motivation to learn in online environments: An exploration of two tertiary education contexts (Doctoral dissertation), Massey University, Palmerston North, New Zealand. Retrieved from http://muir.massey.ac.nz/handle/10179/2043

Hartnett, M., St. George, A., \& Dron, J. (2011). Examining motivation in online distance learning environments: Complex, multifaceted and situation-dependent. International Review of Research in Open and Distance Learning, 12(6), 20-38. Retrieved from http://www.irrodl.org/index.php/irrodl/article/view/1030

Hartnett, M., St. George, A., \& Dron, J. (2014). Exploring motivation in an online context: A case study. Contemporary Issues in Technology and Teacher Education, 14(1), 31-53. Retrieved from http://www.citejournal.org/vol14/iss1/general/article1.cfm

Haythornthwaite, C., \& Andrews, R. (2011). E-learning theory and practice. London: Sage. doi:10.4135/9781446288566

Jang, H., Reeve, J., \& Deci, E. L. (2010). Engaging students in learning activities: It's not autonomy support or structure, but autonomy support and structure. Journal of Educational Psychology, 102(3), 588-600. doi:10.1037/a0019682

Jones, A., \& Issroff, K. (2007). Learning technologies: Affective and social issues. In G. Conole \& M. Oliver (Eds.), Contemporary perspectives in e-learning research: Themes, methods and impact on practice (pp. 190-202). London: Routledge.

Katz, I., \& Assor, A. (2007). When choice motivates and when it does not. Educational Psychology Review, 19(4), 429-442. doi:10.1007/s10648-006-9027-y

Kim, K.-J., \& Frick, T. W. (2011). Changes in student motivation during online learning. Journal of Educational Computing Research, 44(1), 1-23. doi:10.2190/EC.44.1.a

Lee, Y., Choi, J., \& Kim, T. (2013). Discriminating factors between completers of and dropouts from online learning courses. British Journal of Educational Technology, 44(2), 328-337. doi:10.1111/j.1467-8535.2012.01306.X

Loyens, S. M. M., Kirschner, P. A., \& Paas, F. (2011). Problem-based learning. In K. R. Harris, S. Graham, T. T. Urdan, A. G. Bus, S. Major \& H. Swanson (Eds.), APA educational psychology handbook: Application to learning and teaching (Vol. 3, pp. 403-425). Washington, DC: American Psychological Association.

Luppicini, R. (2007). Review of computer mediated communication research for education. Instructional Science, 35(2), 141-185. doi:10.1007/s11251-006-9001-6

Martens, R. L., \& Kirschner, P. A. (2004). Predicting intrinsic motivation. Association for Educational Communications and Technology (pp. 621-630). Washington, DC: Association for Educational Communications and Technology.

Moore, M. G. (2007). The theory of transactional distance. In M. G. Moore (Ed.), Handbook of distance education (2nd ed., pp. 89-108). Mahwah, N.J: Lawrence Erlbaum.

Moos, D. C., \& Azevedo, R. (2008). Exploring the fluctuation of motivation and use of self-regulatory processes during learning with hypermedia. Instructional Science, 36(3), 203-231. doi:10.1007/s11251-007-9028-3

Paris, S. G., \& Turner, J. C. (1994). Situated motivation. In P. R. Pintrich, D. R. Brown \& C. E. Weinstein (Eds.), Student motivation, cognition, and learning: Essays in honor of Wilbert J. McKeachie (pp. 213-237). Hillsdale, NJ: Lawrence Erlbaum.

Patall, E. A., Cooper, H., \& Robinson, J. C. (2008). The effects of choice on intrinsic motivation and related outcomes: A meta-analysis of research findings. Psychological Bulletin, 134(2), 270-300. doi:10.1037/0033-2909.134.2.270

Patton, M. Q. (2002). Qualitative research and evaluation methods (3 ed.). Thousand Oaks, CA: Sage Publications. 
Reeve, J. (2009). Why teachers adopt a controlling motivating style toward students and how they can become more autonomy supportive. Educational Psychologist, 44(3), 159-175. doi:10.1080/00461520903028990

Reeve, J., Ryan, R. M., Deci, E. L., \& Jang, H. (2008). Understanding and promoting autonomous selfregulation: A self-determination theory perspective. In D. H. Schunk \& B. J. Zimmerman (Eds.), Motivation and self-regulated learning: Theory, research, and applications (pp. 223-244). New York: Lawrence Erlbaum.

Rienties, B., Giesbers, B., Tempelaar, D., Lygo-Baker, S., Segers, M., \& Gijselaers, W. (2012). The role of scaffolding and motivation in CSCL. Computers \& Education, 59(3), 893-906. doi:10.1016/j.compedu.2012.04.010

Rovai, A. P. (2007). Facilitating online discussions effectively. The Internet and Higher Education, 10(1), 77-88. doi: 10.1016/j.iheduc.2006.10.001

Ryan, R. M., \& Deci, E. L. (2000). Intrinsic and extrinsic motivations: Classic definitions and new directions. Contemporary Educational Psychology, 25(1), 54-67. doi:10.1006/ceps.1999.1020

Ryan, R. M., \& Deci, E. L. (2002). Overview of self-determination theory: An organismic perspective. In E. L. Deci \& R. M. Ryan (Eds.), Handbook of Self-Determination research (pp. 3-33). Rochester, NY: The University of Rochester Press.

Ryan, R. M., La Guardia, J. G., Solky-Butzel, J., Chirkov, V., \& Kim, Y. (2005). On the interpersonal regulation of emotions: Emotional reliance across gender, relationships, and cultures. Personal Relationships, 12(1), 145-163. doi:10.1111/j.1350-4126.2005.00106.x

Schunk, D. H., Meece, J. L., \& Pintrich, P. R. (2014). Motivation in education: Theory, research, and applications (4th ed.). Boston, MA: Pearson.

Schunk, D. H., \& Zimmerman, B. J. (2006). Competence and control beliefs: Distinguishing the means and ends. In P. A. Alexander \& P. H. Winne (Eds.), Handbook of educational psychology (2nd ed., pp. 349-367). Mahwah, NJ: Lawrence Erlbaum.

Shroff, R. H., Vogel, D. R., \& Coombes, J. (2008). Assessing individual-level factors supporting student intrinsic motivation in online discussions: A qualitative study. Journal of Information Systems Education, 19(1), 111-125

Slavin, R. E. (2011). Classroom applications of cooperative learning. In K. R. Harris, S. Graham, T. T. Urdan, A. G. Bus, S. Major \& H. Swanson (Eds.), APA educational psychology handbook: Application to learning and teaching (Vol. 3, pp. 359-378). Washington, DC: American Psychological Association.

Sørebø, Ø., Halvari, H., Gulli, V. F., \& Kristiansen, R. (2009). The role of self-determination theory in explaining teachers' motivation to continue to use e-learning technology. Computers \& Education, 53(4), 1177-1187. doi:10.1016/j.compedu.2009.06.001

Van Etten, S., Pressley, M., McInerney, D. M., \& Liem, A. D. (2008). College seniors' theory of their academic motivation. Journal of Educational Psychology, 100(4), 812-828. doi:10.1037/00220663.100.4.812

Wegerif, R. (1998). The social dimensions of asynchronous learning networks Journal of Asynchronous Learning Networks, 2(1). Retrieved from http://www.aln.org/jaln/v2n1/social-dimensionasynchronous-learning-networks

Woo, Y., Herrington, J., Agostinho, S., \& Reeves, T. C. (2007). Implementing authentic learning tasks in web-based learning environments. Educause Quarterly, 30(3), 36-43. Retrieved from https://net.educause.edu/ir/library/pdf/EQM0735.pdf

Xie, K., DeBacker, T. K., \& Ferguson, C. (2006). Extending the traditional classroom through online discussion: The role of student motivation. Journal of Educational Computing Research, 34(1), 67-89. doi:10.2190/7BAK-EGAH-3MH1-K7C6

Yin, R. K. (2009). Case study research: Design and methods (4th ed.). Thousand Oaks, CA: Sage.

Corresponding author: Maggie Hartnett, m.hartnett@massey.ac.nz

Australasian Journal of Educational Technology (c) 2015.

Please cite as: Hartnett, M. (2015). Influences that undermine learners’ perceptions of autonomy, competence and relatedness in an online context. Australasian Journal of Educational Technology, 31(1), 86-99. 